\title{
Twelve
}

\section{THEISM AND COSMIC CONTINGENCY}

The Cosmological Argument for the existence of God begins with our awareness of the contingency of things within our world; from this it tries to reason philosophically, not scientifically, to the necessary existence of God. In Process Theism, God's Primordial Nature has necessary existence. Classical and Process Theologians agree that God exists necessarily. The Cosmological Argument expresses a widely shared deep cosmological intuition to the effect that the existence of any contingent thing-anything that might or might not be, ultimately implies the existence of a Necessary Being-one that could not not be. The concept of Necessary Being that applies to God in the Cosmological Argument is the same as the one that applies in the Ontological Argument (which is not here discussed in any detail). Kant maintained, correctly, that the Cosmological Argument depends on the Ontological Argument in one important respect-both employ an a priori concept of God, that is, one that is not derived from sense experience. Thus, if the Cosmological Argument is valid, so is the Ontological; for the Necessary God on whom all actual and possible worlds depends is an everlasting, uncreated, indestructible Reality who could not not exist and whose existence cannot be denied without self-contradiction.

As indicated in Chapter Ten, by definition, contingent beings might or might not exist; if they do exist, they have causes, can be created or destroyed, and normally come into being in or with time. A Necessary Being could not not exist and has no cause, exists self-sufficiently, and is everlasting, uncreated, and indestructible. St. Thomas Aquinas reasoned from the contingency of perceived motion and change, and from contingency itself, to the necessary existence of God. Contingency involves possible or actual nonexistence. Descartes reasoned cosmologically from the contingent existence of his idea of God to the necessity of its referent as its adequate cause; he also reasoned ontologically from the very meaning of this idea of God to the necessity of its referent. If the Cosmological Argument is any good at all, it should be possible to start with any experience of anything that exists contingently, including the whole contingent universe, and infer the reality of God. Formulating and defending an argument that gives adequate expression to this cosmological intuition is difficult. Since Plato, philosophers and theologians have tried and generally failed for a variety of reasons.

This chapter will proceed directly to a contemporary formulation of the Cosmological Argument that has a decent chance to succeed, partly because it avoids suspicious premises of traditional formulations like "There is a Great Chain of Being that leads from the earth at the center of the universe to God above," or "An infinite regress of causes either in time or in the Great Chain of Being is impossible." Saint Bonaventure argued for the impossibility of an actualized temporal infinity. A more influential St. Thomas Aquinas thought 
that the finitude of the past is disclosed only by revelation, not proved by reason. He insisted that the impossibility of an actualized infinity applies only to causes that simultaneously coexist and act within the Great Chain of Being, not to causes that could exist and act successively in an infinite cosmic past. ${ }^{2}$

The following Cosmological Argument from Contingency makes no appeal to these antiquated and highly suspect elements of Thomistic metaphysics. It is perfectly compatible with and builds upon the empirical discoveries and well tested theories of contemporary scientific cosmology; but it goes beyond them. It is philosophy, not natural science.

\section{A Cosmological Argument from Contingency}

The basic premises of a plausible contemporary Cosmological Argument from the Contingency of the world to the existence of God are:

Premise 1: If each of the parts of any whole has contingent existence, then the whole itself has contingent existence.

Premise 2: Each of the parts of nature or the universe as a whole has contingent existence.

Deduction and Premise 3: Therefore, nature or the universe as a whole has contingent existence.

Premise 4: Definition: If something exists contingently, it is causally derived from or dependent on something other than itself.

Deduction and Premise 5: Therefore, nature or the universe as a whole is causally derived from or dependent on something other than itself.

Premise 6: The something on which nature or the universe depends is either the Principle of Plenitude, which requires infinitely many worlds in time and/or space; or it is God.

Premise 7: The something on which nature or the universe depends is not the Principle of Plenitude or infinitely many worlds.

Final Conclusion: The something on which nature or the universe depends is God.

A sound deductive argument actually proves its conclusion if it has both a valid form and all true premises. The above argument is deductively valid. Following discussions will argue that its premises are all true. Thus, the conclusion is true: The something on which nature or the universe depends is God.

\section{A. Naturalistic Metaphysical Options}

If Naturalists wish to attack this argument and establish their own metaphysics, they must prove the truth of at least one of the following propositions that contradict one or more of the premises of this Cosmological Argument from 
Contingency. Not knowing whether one or more of these premises is true or false makes us agnostics, not Naturalists. Lack of knowledge does not establish naturalistic metaphysics or anything else. Naturalists themselves must prove something if their own metaphysics is rationally justified. The burden of proof in philosophy is on anyone who has anything to say, so Naturalists must establish the truth of their own alternatives to Theism. Naturalists could disprove the premises of our Cosmological Argument from Contingency only by showing that any one, perhaps all, of the following propositions are true; but they cannot do so. All of these Naturalistic metaphysical claims are false, as demonstrated in what precedes and in what follows.

1. Each of the parts of some whole has contingent existence, but the whole itself has necessary existence.

2.Some part (or parts) of nature or the universe as a whole has (or have) necessary existence.

3. Nature, the universe as a whole, has necessary existence.

4. Something may exist contingently without being causally derivative.

5. Nature, the universe, is not causally derived from or dependent on anything other than itself; it was caused by nothing.

6. Our system of nature, our universe, ultimately depends on either infinitely many diverse worlds in Supertime and/or Superspace, as required by the Principle of Plenitude, or on God.

7. Nature, the universe, ultimately depends on the Principle of Plenitude's infinitely many worlds.

Therefore, the universe does not depend on God.

Which cosmological claims are best justified, those of Theism, or those of Naturalism? What is the evidence?

The case against naturalistic alternatives to theistic cosmological premises 4 through 7 above has already been made and does not need to be repeated. With respect to 4 and 5 , we already know from earlier discussions that if something exists contingently, specifically our system of nature, it is causally dependent on something other than itself, and that no plausible case can be made for the Big Accident contention that contingent beings can come to exist without a cause, specifically, that our universe just popped into being from absolute nothingness without a cause. With respect to 6 and 7 , we know from Chapters Four through Eight and Chapter Eleven that variations on many worlds metaphysics cannot be defended, and neither can the Principle of Plenitude, so the best explanation for the existence of our world is that God created it. If the Big Accident, the Principle of Plenitude, infinitely many worlds in time and/or space, and so on, are indefensible, as previously established, the God hypothesis remains as the most plausible account of the supreme transcendent, ultimate reality on which our universe depends. 
Only the first two premises of our Cosmological Argument from Contingency need further defense. The third premise is but an intermediate conclusion from these that functions as an additional premise in the wider argument. We must now dispose of the naturalistic options that some necessary wholes are composed entirely of contingent parts, and that some parts of our universe exist necessarily. The remainder of this chapter first develops and defends this part of the Argument, then explores some common objections.

\section{B. Contingent Parts and Wholes}

That all wholes exist contingently if they are composed entirely of contingent parts is universally verified in experience. This is the best reason we could possibly have for thinking that the first premise of our Cosmological Argument from Contingency is true. In absolutely no circumstances do we find wholes having necessary existence when they are composed entirely of contingently existing parts. In fact, we experience no necessary wholes at all.

The notion of a "whole" in this argument is not necessarily limited to well integrated organic wholes; any collection or totality, integrated or not, would probably do; but we will assume hereafter that relevant wholes are integrated in the sense that all their parts have a common ultimate origin and all these parts have causal relations with some other parts of the whole. All the parts of a unitary universe have a common ultimate cause and somehow hang together in linked causal cones. Everything in our universe has a common origin in the Big Bang and, despite relativity and the mutual independence of contemporaries, all existing entities have linked spatiotemporal and cause/effect relations with at least some other members of our universe.

The empirical first premise of our Cosmological Argument is an inductive generalization from observed wholes to all wholes. Like all inductive empirical claims, it might prove false in some as-yet-undetected situation. Admittedly, we have not empirically tested absolutely all existing wholes. Cosmological arguments that contain empirical premises are infected by the same sort of uncertainty that plagues all inductive inferences. Nevertheless, our first premise is just as well established as any and all other scientific generalizations like Einstein's " $\mathrm{E}=\mathrm{mc}^{2}$," or Hubble's "The whole universe is expanding," or thermodynamics' "Disorder always increases in closed systems." After all, we have not empirically tested all the mass/energy in the universe, or its universal expansion, or the entropy of all closed systems; but as far as experience takes us, these generalizations are universally confirmed, without exception. Hubble's law of uniform expansion is found to be true one hundred percent of the time because, excluding galaxies that are gravitationally bound to our Milky Way or to other galactic systems, all galaxies are moving away from us and from one another at speeds proportional to their distance. 
Surface appearances may suggest that the contingency of all wholes composed entirely of contingent parts is even better verified than Einstein's energy/mass equation. Some astrophysicists affirm that photons, which carry the energy of light, have no mass; and this may be true of some other strange particles as well. ${ }^{3}$ If photons have energy but no mass (even if only in an idealized rest state), then it is not universally the case that $\mathrm{E}=\mathrm{mc}^{2}$, for $\mathrm{E}$ cannot equal $\mathrm{mc}^{2}$ where there is no $\mathrm{m}$. Actually, photons have zero mass only in a purely hypothetical state of rest; and in that ideal state of masslessness, they are energyless as well. This purely hypothetical state must be expressed by a zero on both sides of Einstein's equation, but real photons are never purely at rest. All real photons have both mass and energy; so no anomaly here challenges $E=\mathrm{mc}^{2}$.

Similarly, one hundred percent of the time, as far as experience takes us, if each of the parts of any integrated whole has contingent existence, then the whole itself has contingent existence. This empirical truth could actually count as a scientific truth except that scientists traditionally have not been interested in it. Wolfhart Pannenberg points out that scientists ignore contingency and concentrate instead upon formulating natural laws or uniformities. ${ }^{4}$ As Aristotle indicated, the sciences carve out limited domains of being as their subject matter, while philosophy is concerned with truths that apply universally to everything. The contingency of all wholes with completely contingent parts is true of all empirical subject matter; it applies to all the parts of and to the whole of contingent existence. In my "Philosophy of Religion" courses, I regularly offered to give students an " $A$ " on the spot if they could identify a directly or inductively verified instance of an integrated whole that exists necessarily even though all of its parts exist contingently. I never gave the "A."

Critics may object that our first premise applies only to finite wholes but not to the universe as an infinite whole. All finite wholes composed entirely of contingent parts are themselves contingent, but this may not be true of infinite wholes. We cannot reason inductively from the finite to the infinite. Thus, if the universe is an integrated infinite whole, it could have necessary existence even though composed entirely of contingent parts.

That the universe is an infinite whole is logically possible, but this could never be verified either directly or inductively, and the evidence to the contrary is overwhelming. Remember the Big Bang! Verification and falsification move far beyond toying around with possibilities. Possibilities are not actualities, and they should not be confused with probabilities. We definitely do not know that the universe is an infinite whole. Even if it is, we could never know or verify the claim, and Big Bang Cosmology provides convincing evidence that the universe is not an infinite whole. Temporally, the universe is only fifteen billion or so years old; spatially, though astronomically immense, it is finite but expanding-finite in actuality, even if infinite in potentiality.

Mathematicians tell us that any line has an infinite number of parts (Euclidean points); and each sub-section of a line contains just as many parts as the 
whole. Since lines depend for their existence upon the causes that draw them, or on the mathematicians that imagine them, we know that theoretically infinite wholes, those composed of an infinite number of parts, exist contingently.

Yet, according to quanturn discreteness, mass/energy cannot actually be sub-divided below the spatiotemporal minimals of Planck dimensions. Particles exists and energy is transmitted in minimal quanta or not at all; even space has an irreducibly granular quality. Thus, no actual line drawn in the objective world is an infinite physical continuum. Observed quantum-atomized lines are not infinite as wholes actually having an infinite number of parts; but this is not incompatible with our first premise.

Conceptually constructed imaginary lines are only potentially infinite wholes with potentially infinite parts; but they depend for their existence upon conscious thinkers or imaginers. Since infinite wholes with potentially infinite parts exist contingently, and we know of no instances to the contrary, the universe as a whole should be contingent if it has an infinite number of parts only potentially. We cannot generalize from potentiality to actuality, and the thought of infinity, dependent on the mind of the thinker, is not an actual infinity. The actual thought of "infinity" is not an actual infinity of thoughts; it is only one thought, just as the actual thought of "blue" is not a blue thought.

Note carefully that our Cosmological Argument from Contingency makes no appeal to the contingency of actually infinite wholes, for our universe is definitely finite. It is not actually infinite in any respect. According to Big Bang Cosmology, our universe is vast; but it is finite in expanse, past duration, mass, and in all other denumerable ways. The Planck-dimension minimals of quantum physics prohibit this finite mass from being actually divisible into an infinite number of real parts. Naturalists can identify no necessary infinite wholes composed entirely of contingent parts. Our universe is certainly not such an infinite whole, and it does not have an infinite number of parts. All experienced finite wholes composed of contingent parts are themselves contingent. This empirical truth can be generalized inductively to include our universe. Protests will be explored later.

The Cosmological Argument from Contingency may be defective just because it reasons from parts to the whole of nature. Logic texts say that reasoning from parts to wholes commits the informal logical Fallacy of Composition, according to which inferring that a whole possesses a certain property merely because each of its parts possesses that property is erroneous. Despite what introductory logic texts say, it is not always fallacious to conclude that a whole possesses a property because all of its parts have that property. Sometimes so to reason really is a mistake, but sometimes not. How can we tell the difference?

Arguments from parts to wholes can be formulated, or reformulated, as deductive arguments. Unjustified conclusions can be drawn from deductive arguments in at least two ways. First, the argument form or pattern may be invalid; second, one or more of the premises may be false or not known to be 
true. The first three of the following arguments are obviously erroneous; but what kind of a mistake do they make?

\section{Argument I.}

(1) If all the microscopic parts of a machine are invisible to the naked eye, the whole machine is invisible to the naked eye.

(2) All the microscopic parts (atoms) of this car are invisible to the naked eye. Therefore, this whole car is invisible to the naked eye.

\section{Argument II.}

(1) If all the microscopic parts of a body (the cells, molecules, atoms, and so on) are devoid of consciousness, the whole body is devoid of consciousness.

(2) All the microscopic parts of my body (the cells, molecules, atoms, and so on) are devoid of consciousness.

Therefore, my whole body is devoid of consciousness. ${ }^{5}$

\section{Argument III.}

(1) If each of the elemental parts of a chemical compound is a gas, the whole compound is a gas.

(2) Each of the elemental parts of water (hydrogen, oxygen) is a gas. Therefore, water is a gas.

These three arguments from parts to whole obviously fail to prove their conclusions. The next two arguments also move from parts to wholes, but they are not faulty. They commit no fallacy; they involve no falsehoods or uncertainties; and they show that we can reason successfully, deductively, and correctly from parts to wholes.

\section{Argument IV.}

(1) If all the macroscopic parts of a machine are made of metal, the whole machine is made of metal.

(2) All the macroscopic parts of this water pump are made of metal.

Therefore, this whole water pump is made of metal.

Argument $V$.

(1) If each island in a group is in the Pacific Ocean, the whole island group is in the Pacific Ocean.

(2) Each island in the Hawaiian group is in the Pacific Ocean.

Therefore, the whole group of Hawaiian Islands is in the Pacific Ocean.

No fallacious pattern of reasoning is involved in any of the above arguments. They all involve an instantiation with respect to particulars and manifest the valid pattern of modus ponens: If $\mathrm{p}$, then $\mathrm{q}$; and $\mathrm{p}$; therefore, $\mathrm{q}$. What then is the 
error in arguments I, II, and III that is absent in IV and V? The first three do not contain any ambiguous concepts, though logic textbooks regularly but mistakenly classify the Fallacy of Composition as a Fallacy of Ambiguity. The only difference is that the first premises of I, II, and III are false, as shown by experience; but experience confirms the first premises of arguments IV and V.

Our Cosmological Argument from Contingency is a valid deductive argument that commits no informal logical fallacy. Its first premise resembles the first premises of IV and V, not those of I, II, and III.

Some reasoning from parts to wholes is illegitimate, some not, depending on the formal pattern of reasoning and/or the truth or falsity of the premises. We cannot correctly infer that a whole machine is invisible because each of its atomic parts is invisible, or that a whole body lacks consciousness because each of its cells lacks consciousness, or that a compound is a gas because each of its elemental parts is a gas, or that a whole machine weighs one pound because each of its ten parts weighs one pound, or that a whole painting is beautiful because each of its parts is beautiful. Yet, we can infer correctly that a whole macroscopic machine is made of metal because each of its macroscopic parts is made of metal, that an island group is in the Pacific because each island is in the Pacific, and that a whole chair is painted green because each of its visible parts is painted green. With a valid argument form, these inferences commit no logical fallacy. The only legitimate question is whether the premises are true. In IV and V, experience shows that the premises are true; and because the forms are also valid, the conclusion is proved. ${ }^{6}$

Some properties like being metal, being in a geographical area, and being a certain color can be inductively extended or extrapolated from parts to wholes; and others, like being invisible, being conscious, weighing a pound, and being beautiful, cannot. Experience tells us which is which.

Contingent existence is an extrapolatory property, as experience also invariably shows. If each of the parts of any whole has contingent existence, we know from experience that the whole itself has contingent existence. We know that its non-existence is logically conceivable, that its mode of being is not selfsufficient but depends on some cause or causes, that it has not existed forever, and that it is destructible and will probably cease to exist at some point in the future. This includes wholes that are combined into even larger wholes up to infinity, and perhaps including infinity (though infinity is irrelevant to our finite cosmos). Verifying experiences support the first premise of our Cosmological Argument from Contingency one hundred percent of the time; and the form of the argument is perfectly valid. This is as good as philosophical arguments ever get! Our intermediate conclusion-nature, the universe, has a contingent form of existence-will follow if the second premise is true, that is, if there are no necessary parts of the universe. Naturalistic metaphysics from the time of the Greek atomists has been based partly upon the possibility of finding some necessary part(s) of nature; but the enterprise is futile! 


\section{No Necessary Parts of the Universe}

The second premise of the Cosmological Argument from Contingency affirms that all parts of nature are contingent. Is this false or at least not known to be true? The universe would not be a whole composed entirely of contingent parts if some of its parts exist necessarily. Naturalists often make this claim, but they must do much more than just proclaim it. They must actually show that some parts of the universe exist necessarily. The burden of philosophical proof is not always on the Theist. It is on anyone who has anything to say.

Naturalists agree with everyone else that all macroscopic bodies like stars, planets, and human bodies are contingent. They locate the necessary parts of nature in its microscopic innards. The naturalistic presumption that the necessity of the universe is situated in the subject matter of particle physics was never effectively challenged before the twentieth century. The Greek Atomists and naturalistic Materialists through the centuries believed that spacetime itself and its most primitive contents, the atoms, exist necessarily; the atoms and the infinite void are self-sufficient, everlasting, uncreated, and indestructible. Atomists once called the smallest particles of matter "atoms" and pronounced them necessary beings, but we now know that they are not. Exactly which parts of matter get classified as "smallest" changes as our knowledge of sub-atomic physics advances; but nothing at atomic or sub-atomic levels exists necessarily.

Particle physics gave naturalistic metaphysics an enormous shock in the twentieth century. Traditionally, naturalistic confidence in the eternity and necessity of the world presumed that the most primitive particles of matter are self-sufficient, everlasting, uncreated, indivisible, and indestructible. Physics today finds no physical particles or sub-particles that have such attributes, not those now called "atoms," and not their more primitive sub-atomic components. All physical particles exist only derivatively or contingently. Some endure only for only thousandths or millionths of a second. Nucleosynthesis and nuclear fusion bring all atoms and all their sub-atomic parts into being, so they haven't been around forever; and nuclear fission can destroy them all and convert them into energy or other particles or forms of radiant energy.

The Greek Atomists were totally wrong in thinking that the smallest physical particles have always existed unchanged and uncreated. We now know that even the smallest parts of atomic nuclei, the quarks, exist contingently, and so do the electrons that orbit atomic nuclei. Quarks always come in pairs (in mesons) or three at a time (in protons and neutrons). Pairs or triplets of quarks cannot be separated, but they can be created and destroyed. Bombarding them with larger particles in accelerators to try to separate them merely creates additional pairs or triplets of quarks out of the exchange of kinetic energy. Quarks can thus be created in the laboratory out of energy; and anything that is or can be created in the laboratory or elsewhere has a merely contingent form of existence. Quarks are not necessary beings, and neither are electrons, which can 
also be produced and destroyed by the same processes. One type of quark is called the "Higgs particle," or "Higgs boson." In defending Naturalism, specifically its claim that our universe is eternal, Kai Nielsen wrote,

Even if the big bang theory is true, it does not show that the fundamental particles were brought into explosive existence by the big bang. The Higgs particle need not be thought to have so come into existence, or to have come into existence at all, and it stands as a candidate for a necessary being and a more plausible one than God.?

On the contrary, innumerable articles in the literature of physics describe the production of Higgs particles in cyclotrons under many different conditions. ${ }^{8}$ No kind of entity that is or can be produced by something else is an eternal, selfsufficient, and necessary being. Also, Big Bang and Grand Unification Theories say that in the beginning all existing particles emerged from a more primitive state of unified pure energy, which in turn had its own cause.

The most stable and enduring sub-atomic particle is the proton. Once created, protons last for billions of years. The protons in the nuclei of most atoms existing in the material world today were created within the first three minutes after the Big Bang, but they were created. Most physicists believe that protons eventually decay; but elaborate experiments designed to detect proton decay have failed thus far. Nevertheless, protons are not eternal and necessary beings. They are composed of quarks, and quarks are not eternal and uncreated. Protons may naturally decay very slowly, but they can be destroyed in proton/antiproton collisions and in nuclear reactions. In fact, any kind of particle can be destroyed by its antiparticle; and all particles and antiparticles were created after the onset of the Big Bang by the primordial grandly-unified matterless, particle-less energy that preceded them. The same is true of the four basic forces of nature that once were one, says Grand Unification Theory. No created and destructible entity or force is a necessary being.

Though all particular physical entities exist contingently, perhaps spacetime and/or pure physical energy exist necessarily. No, spacetime and physical energy also exist contingently if the Big Bang originated in a singularity of nothingness totally devoid of spacetime and energy, or if the Big Bang and all its contents were created at some point in the past by anything whatsoever. So what caused the Big Bang?

In contemporary physics, space, time, and physical energy are inseparable; but the emphasis is on time. Time has not been spatialized; rather, space has been temporalized. Neither space nor time are merely empty forms into which actual events and particles are infused. Space is not vacuous nothingness; it has its own energy density; it is an elastic physical reality that may be warped, stretched, condensed, straightened, curved, expanded, and contracted to nothingness (almost?). All physical particles and configurations of energy are 
constituted by both time and space. Particles, waves, and all microscopic entities are warped, knotted, or stringed concentrations of spacetime. In contemporary physics, neither atoms nor any sub-atomic particles, waves, fields, or other entities are basic necessary beings.

As Werner Heisenberg indicated, in contemporary science, energy is "The primary substance of the world."' Is energy the necessary being? No. According to the Standard Model of Big Bang Cosmology, space/time/mass/energy was created in the beginning out of what was empirically nothing-often called an initial singularity. No alternative cosmology actually proves otherwise. If our universe emerged from an initial singularity, neither spacetime nor physical energy exist necessarily. Yet, other possibilities remain to be examined.

Perhaps pure energy as such exists necessarily, though all particular forms of energy exist contingently (as suggested by the quotations from Corliss Lamont with endnote numbers 15 and 16 in Chapter Two). Electrical energy is derived from dynamos; atomic energy is derived from nuclear reactions; solar energy is derived from the sun. Every empirically observable manifestation of energy is derived from some energy source other than itself. Having a derivative existence is precisely what existing contingently means.

Does pure (non-empirical) energy as such exists necessarily? If so, it is too pure to count as something empirical or observable! All observable forms of energy exist contingently, being derived causally from something else, from other forms of energy. Furthermore, all of these emerged initially from, were caused by, the Big Bang. So we are back to our original problem, What caused the Big Bang? It was something transcendent, something outside our spacetime system, something beyond nature! Naturalists, like Theists, resort finally to explaining things visible (natural) in terms of things invisible (non-natural). Not all natural effects have naturai causes. Naturalist and theists have their backs to the same wall.

One hundred percent of the time, verifying experiences confirm that all parts of the universe exist contingently. True, we have not tested every last part of the universe, just as we have not tested every last speck of energy to verify that $\mathrm{E}=\mathrm{mc}^{2}$. Neither proposition is absolutely certain, but both are as well confirmed as anything that we know.

Indisputably, if space/time/mass/energy originated at some point in the finite past either from nothing or from extra-natural antecedents, our whole universe and all its parts exists contingently. This is exactly what Big Bang Cosmology proclaims. Neither any parts of nature nor nature as a whole are necessary, self-sufficient, uncreated, everlasting, and indestructible. Even a reified infinitely transcendent Superspacetime/mass/energy would exist contingently if it were wholly comprised of contingent parts. An infinite whole composed of an infinity of contingent parts is an infinitely contingent whole, not a necessary being, but this can be disputed. Let's try to imagine how. 
Assume for the sake of the argument that Oscillation Cosmology's claim that later universes are caused by antecedent universes at least makes sense, even if unverifiable. Even so, "Any whole is contingent when composed entirely of contingent parts," applies to all combinations of contingent antecedent universes linked by a common thread of causation. Let our world of nature, our universe, be U1; and let it be our first whole, W1. Let U1 be caused by an antecedent universe, U2, which is our second whole, W2. Together they will form a Third whole, W3. If both universes are themselves contingent, W3 will also be a contingent whole. This process can be repeated any number of times, perhaps even an infinite number of times, and all repetitions will be swallowed up by the premise: if any whole is composed entirely of contingent parts, the whole itself is contingent. We will return to this later in replying to objections to the Cosmological Argument.

Our universe as a whole does not have a necessary mode of existence. The first two premises of our Cosmological Argument from Contingency are true, and its logical form is valid. Our universe does not exist necessarily, and Naturalists are wrong in believing otherwise. All wholes, including our universe, composed entirely of contingent parts are contingent wholes; and our universe is composed entirely of contingent parts. Therefore, our whole universe exists only contingently. Once established, this deduction is used as an additional premise in our more extended Cosmological Argument from Contingency.

Theology is not tied inextricably to creation ex nihilo, even if it now seems to be a very reasonable position. A theology for rational persons must be compatible with the most firmly established conclusions of the natural sciences, but theology should proceed with caution in binding itself too tightly to particular scientific theories, concepts, and discoveries. Sometimes, a healthy agnosticism, an open mind, is the most reasonable theological response. Still, the preponderance of evidence as we see it cannot be ignored. All philosophical knowledge falls short of certainty; but we want the most reasonable belief about what caused the Big Bang that we can find; and our best informed guess is that creation ex nihilo by God is it.

Two basic options, (1) creation out of nothing and (2) out of spatiotemporal antecedents, are now both available to Process Theologians, who traditionally presupposed something like theistic oscillationism. Whitehead said that God does not exist before the world but always with the world-some world. Yet, creation ex nihilo is a viable process option, as explained in Chapter Ten. From the perspective of Superspacetime, God could create all worlds either out of nothing, out of his own Superspatiotemporality, or out of the ashes of antecedent universes. No matter which, we could expect God to choose laws and initial conditions that would make each world interesting and worthwhile.

But our own world is our most immediate problem. Do we know enough at this point to draw any conclusions about it? Is it a necessary being? A contingent being? Did it have a cause? What really caused the Big Bang? 


\section{Conclusion: The Dependence of the Universe on God}

Our Cosmological Argument from Contingency concludes that nature, the universe, our system of spacetime, ultimately depends on God. St. Thomas Aquinas said that the ultimate cause and designer of the universe is what "all men call God"; but this is really not true according to Naturalists. They don't call it God! St. Thomas also said that the Cosmological Argument can tell us that God exists but not what God is like, nothing about God's essence. If so, it generates very little useful or valuable information about God. Actually, taken with the Teleological Argument, it does tell us some religiously significant things about God. Together these arguments inform us that our contingent world of nature requires a cause that is (1) transcendent, (2) immensely powerful, (3) creative, (4) necessary, (5) infinite, (6) intelligent, (7) purposive, and (8) benevolent. All arguments for the existence of God must work together to give us this much information. The Cosmological Argument gives us (1), (2), (3), (4), and (5); and the Teleological Argument gives us (6), (7), and (8). Only the Ontological Argument (not explored in depth in this book) ${ }^{10}$ can give us all divine perfections, including (9) perfect virtue or optimal righteousness, (10) supreme holiness, and so on. All three of these arguments taken together bring us to an ultimate Divine reality in whom all our questions about why there is something rather than nothing finally come to rest. On rational grounds, they bring us to God as the supremely worshipful, creative, everlasting, uncreated, and indestructible Ultimate Reality who could not possibly not be.

\section{Critique of the Cosmological Argument from Contingency}

Replies to several important objections to the Cosmological Argument were implicit in many earlier discussions. We now know that our universe is not a Big Accident having no cause at all, that it is not a chance occurrence within infinitely many worlds, and that cosmological reasoning from the world to God does not commit the informal logical Fallacy of Composition. The following additional charges must now be confronted. A. An everlasting universe needs no God. B. Contingent wholes imply only contingent causes. C. God must have a cause if everything has a cause. $D$. The concept of the universe as a whole, and thus of God's creating it, is meaningless. E. Transcendent reality is unknowable. Can plausible replies be given?

\section{A. The Universe Needs No God}

If creation ex nihilo is true, the universe as a whole and all its parts depend on God for their very existence since God created all the primoridal spacetime/ mass/energy of our universe from nothing. Many atheistic oscillationists assume that the universe, some universe, has always existed, and that an everlasting set 
of successive universes is itself a necessary being that needs no God. As we saw in Chapter Four, Oscillation Cosmology is often adopted mainly to avoid God, but it may not be true that an everlasting universe or set of universes would not be contingent upon God in any respects, and it is definitely not true that ours is an everlasting universe or that it belongs to an everlasting set of sequential universes.

The evidence already given is overwhelming that our universe is finite but expanding spatiotemporally, and it is not divided into an infinite number of tiny but real parts, some of which exist necessarily. The contingency or derivative existence of the universe might not depend totally upon its finitude in time or space. Naturalists suppose that the universe (or some universe) has infinite temporal duration. This means, they conclude, that our universe exists necessarily; but they are mistaken. Unlike ours, an eternal universe might resemble necessary existence in being uncreated and everlasting, yet it would still be causally contingent if it depends everlastingly in some way on something transcendent.

Traditional theism says that God both created the world and continues to preserve or sustain its existence. The world depends on God originally and at every moment. Either (or both) implies that the universe has a contingent or dependent form of existence and that God is the world's ultimate necessary condition. Theism is not inescapably tied to creation out of nothing in the finite past or to Big Bang Cosmology. The universe would have a derivative or causally dependent mode of being if either of the following propositions is true:

(1) The whole universe came into being at some point in the finite past; and/or

(2) The universe, or other universe(s) to which ours is connected, depend somehow on God at some or all moments throughout an infinite past and/or an endless spatial expanse.

If all contingent wholes in a finite or an infinite series depend on God either originally, continuously, or historically in any way at all, the claim that "All wholes within the universe are caused by contingent beings" is only part of the truth. The whole truth adds, "and by a necessarily existing God."

St. Thomas Aquinas believed on the basis of divine revelation (as he interpreted it) that (1) is true; but, he contended, the Cosmological Argument for God hangs on the second type of contingency, not the first. Aquinas thought that Aristotle, for whom the world co-existed eternally with God, set the definitive standard for what reason could or could not accomplish. In deference to Aristotle, Aquinas held that reason cannot prove that the world has a beginning or disprove its everlasting co-existence with God. Revelation may say otherwise, but not reason. A world co-existing with God throughout an infinite past would nevertheless depend infinitely on God for its order and being, just as rays from the sun would depend infinitely on the sun if the two co-existed forever. Though Aquinas did not say so, a spatially infinite universe would also be 
contingent if it somehow depends on God at any or at every real unit of spatial extension. An infinitely prolonged or extended set of contingencies does not add up to necessity, especially where causal dependence exists at spatial and/or temporal units along the way. An infinite spatially and/or temporally contingent world is not a necessary being; it is an infinitely contingent being. For many good reasons, now we know that we do not live in an infinite world.

St. Thomas Aquinas anticipated neither contemporary Biblical criticism nor Big Bang Cosmology. Perhaps he was wrong in thinking that revelation teaches creation ex rihilo in the finite past, and that reason cannot show that the universe originated at some point in the finite past. Modern Biblical scholarship affirms that creation ex nihilo is not clearly taught in Genesis or elsewhere in the Protestant Bible; and Big Bang Cosmology shows that the universe, the whole shebang, was created in the finite past-about fifteen billion years ago.

St. Thomas was convinced that creation ex nihilo is a clear deliverance of Christian revelation, " but this is far from certain. Modern Biblical scholars generally agree that the first chapter of Genesis does not clearly affirm creation out of nothing. In the King James translation of the Bible, the first verses of Genesis read, "In the beginning, God created the Heavens and the earth; and the earth was without form and void." Biblical scholarship in the twentieth century concludes that these verses may, with perfect faithfulness, be translated to read, "When God began to create the Heavens and the earth in the beginning, the world was without form and void." In margins or notes, current translations of Genesis give this as a perfectly legitimate rendition of Genesis 1:1. Genesis declares that God created the universe, not ex nihilo, but out of the formless chaos that already existed "when God began to create." Creation itself was initiated only when God said "Let there be light." In Genesis, at the beginning, God brings order to the world but does not bring it into being absolutely. God is a world-designer but not a world-creator.

Although not clearly taught anywhere in what Protestants recognize as the Bible, creation ex nihilo is taught perhaps in the intertestamental literature that Protestants do not regard as scriptural, though Catholics do. Specifically, the idea seems to occur for the first time in II. Maccabees, Ch. 7, verse 28, which reads, "I beg you, child, look at the sky and the earth; see all that is in them and realize that God made them out of nothing, and that man comes into being in the same way." 12 This was written perhaps as early as 125 B.C., but scholars debate its date. St. Thomas Aquinas regarded II. Maccabees as scriptural, but the authors of the "Westminster Confession," along with most Protestants, did not and do not so regard it. In any event, Eric Lerner's assertion that creation $e x$ nihilo originated with Tertullian in the third century A.D. is incorrect. ${ }^{13}$ As far as biblical religion is concerned, God ordered the universe from pre-existing chaos, which may have co-existed everlastingly with God. The God of Genesis, like Plato's Deimurge in the Timaeus, ordered the world out of pre-existent 
materials. Neither created the universe out of nothing. Still, creation ex nihilo might be true in spite of Genesis.

\section{i. Creating and Sustaining}

To return to philosophy again, how might a created or a continuously existing universe or everlasting set of universes depend on God, and how much of it makes sense within the framework of Process Theology?

(1) The first and most obvious way in which the universe depends on God is with respect to its creation, its existence. If God created our universe out of nothing, Process Theologians must join with Classical Christian Theologians in recognizing the most obvious way in which our universe depends upon God. God produced from nothing the very stuff of physical existence, all the space/ time/mass/energy of creation. Except for God's creative activity, there would be no space/time/ mass/energy, no chain of secondary causes within the world, no world to sustain. Creation out of nothing does not explain how God sustains all creation, but it is the most conspicuous way in which the world depends on God.

Traditionally, Process Theologians repudiated the claim that God creates our world out of nothing; but from the revised process perspective developed in Chapter Ten, Process Theology can incorporate creation ex nihilo. Thereby it can further enrich its understanding of how the world depends on God. Creation out of nothing and ongoing providential directing were emphasized traditionally by Classical Theologians, but Process Theologians can also make a prominent place for them.

(2) Closely related to depending on God for its existence is dependence on God for its form, its life-supporting law and order or structure. Some important features of original creation are ongoing. Our teleological inquiries show that our universe depends on the intelligent and purposive foresight of a being of divine proportions for its life-producing and preserving law and order, its lifefavoring natural laws or habits. If natural laws are only statistical abstractions from the collective habits of massive numbers of kinds of things like electrons, protons, photons, paramecia, and people, then claiming, as Charles Hartshorne did,${ }^{14}$ that God chooses natural laws for our universe or cosmic epoch is just a roundabout way affirming that God created a plurality of creatures having certain natures which, on average, behave in certain calculable ways. Hartshorne was well aware that natural laws are formal, statistical, and changeable; but he might not have appreciated fully the very concrete causal efficaciousness involved in this claim. This means that God selects and produces not the lawful forms as such, but the basic kinds of entities that exist. God gives them the natures that their habits express statistically. The basic structures and habits of existing things can evolve, along with the laws that express these changes. Today's "scientific" cosmologists agree that no laws for physical particles 
existed before particles separated from the grand initial unification; and no laws of human psychology existed before human beings evolved. Still, the "hand"the anticipations, intentions, and influences-of God is in all of this. In formatively influencing the natures of things that act lawfully in nature, God acts as an efficient cause of particular kinds of entities, not just as the final cause of the abstract lawlike patterns that describe their activities.

Our universe depends on God for its basic life-supporting structural features, its original life-assuring initial conditions, including its initial low entropy, the kinds and strengths of its basic physical forces, its asymmetry of matter over antimatter, and many other initial conditions previously discussed.

If ours belongs to an extended set of oscillating universes (as seems unlikely), there might be a place after for a God of the Gaps, especially if the gaps fall between or at the beginning of universes. Science can know only our own cosmic epoch. Existing originally only in the Primordial mind of God, beneficent life-favoring natural laws (general patterns) and initial conditions could vary in and need to be chosen anew for each cosmic epoch. As we know and discover them, the formal patterns of the enduring habits of primitive physical entities in our universe are expressed in the laws of physics, chemistry, biology, psychology, and the other natural and social sciences. The earliest emergent laws of nature and the original conditions of the universe belong more to initial creation than to continuous sustenance, but they or their effects persist even today. Here the Cosmological Argument (dependence) merges with the Teleological Argument (purposefulness). The beneficent order of nature is both ongoing and evolving.

(3) Theologians have held that God sustains the world in being whether created or everlasting. If the universe in some form existed infinitely into the past, might it still depend on God? Many cosmologist seem to believe that this would be a way avoiding God. Not so! St. Thomas Aquinas, the most influential classical theologian, strongly believed that if our world existed throughout an infinite past and depended on God for something through it all, it would definitely be contingent upon God, just as rays coming from the sun would depend infinitely upon the sun if they co-existed throughout an infinite past. This analogy would also hold for a modern process theistic oscillation cosmology in which each member of an infinite set of successively existing worlds somehow depends on God. But how could an infinite past actuality or chain of past actualities depend on God in the absence of original creation from nothing?

The classical answer that God constantly sustains or preserves the world in existence might do the job if we really understood what "sustains" means and were sure that an infinite series of contingencies lacks the ability to sustain itself, or that physical mass/energy, once created, lacks the intrinsic self-existence attributed to it by the First Law of Thermodynamics. The meaning of "God preserves" has been difficult to specify. We definitely cannot argue 
without circularity that the world cannot sustain itself because it depends on God, for that is precisely what is at issue. That is what must be clarified.

Most attempts to explain the meaning of "God sustains the world" get no further than identifying sustaining with continuous creation, preservation, or dependence, all of which are then defined as sustaining. Getting beyond this conceptual circularity is extremely difficult.

Consider briefly some implausible analyses of what it means to say that "God sustains the existence of all creation." Since sustaining applies to everything in the universe, an account of how it works must have universal significance and application. Because they have only local significance and application, particular miracles (if any) and acts of providence (which are not necessarily miraculous) do not count as sustaining. Sustenance belongs to general providence, not to particular providence.

Some explications of how God sustains the universe are clearly implausible. (A) Perhaps new matter/energy is constantly being created everywhere, as suggested by Fred Hoyle, except God rather than matter is its cause. Yet, little or no evidence supports such ongoing violations of the principle of the conservation of energy. This may or may not happen occasionally at that fuzzy borderline between potentiality and actuality that the physicists call the space/time "vacuum" where the world merges with God. If it happens constantly, the pace of it is too slow to account for the entire mass of our universe within finite Big Bang time.

(B) Perhaps, as Bishop Berkeley and Quantum Observer Theorists maintain, an actual world exists only as something being perceived either by ourselves, by other finite minds, or by God, who is always around to keep things going when no one else is looking. The universe would cease to exist if God quit thinking or perceiving it if Idealists are right. For Idealists, God's sustaining the world just consists in his continuing to think it. Yet, this book opts for and defends a critically realistic theory of knowledge and a corresponding realistic metaphysics.

(C) Perhaps sustaining is just constant recreation every instant, as Descartes and a few others maintained. Jonathan Edwards, who held this view, argued that no real causal relations obtain at all between events within the world; the world continues to exist because God recreates the whole of it from nothing at every moment. ${ }^{15}$ Edwards anticipated David Hume's empirical reduction of causation to mere temporal succession and spatial contiguity devoid of "secondary" causal efficacy. Yet, despite Edwards and Hume, things within the universe do seem to have real causal relations and connections. Existing entities really do transmit their energy, structured patterns, and purposes to other things; and constant recreation just seems like a lot of unnecessary repetitive work for God. So does creating a world that is not self-sustaining once created.

(D) Traditional theology simply decreed that created things in themselves lack the power to continue to exist and that God alone supplies that power. 
Naturalists regard this as question-begging; and Theists who say this must explain how God supplies things with the power to exist, which is not accomplished simply by declaring that he does. Theists might hold that God made the universe to be self-sustaining, once created, that God himself is behind the first law of thermodynamics. Once created, the world's mass/energy cannot be destroyed. Perhaps making it so from the outset is one of God's ways of sustaining creation.

"Sustaining" is a difficult concept to make intelligible. Process Theology's distinctive accounts of how the world depends on God can be construed as ways in which God constantly sustains creation. According to process thought, God does not act on the world merely at the beginning. Rather, God continuously interacts with it, and it constantly depends on God in a variety of ways. God's influence on the world is ongoing. How so?

\section{ii. Influencing and Saving}

How else might a universe or many universes depend on God? Are other accounts of "sustaining" more plausible? Some forms of dependence belong to initial creation, some to ongoing preservation. Perhaps ongoing preservation is ongoing creativity. The several ways in which the world depends upon God according to Process Theism may help to make sense of the vague notion of "sustaining the world." As mainstream Process Theologians contend, God continues to influence creatively and include within himself the course of events within the world, so sustaining is ongoing creation and preservation. But how does this happen?

(1) Temporal entities within the world rely on God to supply them with an "initial aim," consisting of an awareness of novel possibilities for creative activity and self-development. Efficient causation within the world is mixed with final causation, purposiveness, or teleology derived from God.

(2) Temporal entities depend on God to lure them gently toward goodness, without overwhelming their ability to choose otherwise. Alluring visions or intuitions of the true, the beautiful, the right, and the good within the world ultimately come from God. Higher or more complex organisms like us clearly have them, but their pervasiveness is open to debate. In our awareness of and sensitivity to values that transcend time and place, God's presence is ongoing.

(3) All individual events depend on God's memory for the preservation of their concrete being and value once they perish in time to themselves. Every universe, if others exist, depends on God to preserve all intrinsic, extrinsic, and systemic worth achieved within it. Without God, contingent goodness perishes altogether with the passage of time. Divine value-conserving activities are ongoing, universal, and count as "sustaining." By remembering them flawlessly, God sustains and conserves within himself all values actually achieved in 
ongoing creation. Plausibly, sustaining is God's remembering. This way of sustaining the world is its eternal salvation.

(4) Finally, once the mass/energy of existence is created, God voluntarily shares creativity itself. Newtonian universes devoid of creativity are logically possible, but God grants freedom and co-creativity to his creatures. The transition, transmission, and transformation of mass/energy belongs to the subject matter of physics; the internal self-creation of actual entities belongs to psychology, axiology, metaphysics, and theology. Self-creation and final causation or persuasion may not apply everywhere, but they are widely distributed. In originating universes, in creating the intensely concentrated stuff out of which partly self-creative actual occasions emerge, God acts only as an efficient cause without imparting final causation to existing subjects, without giving initial aims to pre-existing individuated occasions, for none exist at the initial moment of grand unification and perhaps for some time thereafter. Non-existence and nonindividuation cannot be co-creators with God; but very near the outset of a Big Bang, individuated entities in a newly created ex nihilo universe could be. God caused and designed the Big Bang, and the Big Bang produced both freedom and order.

(5) Plausible versions of both Classical or Process Theology may make a place for special acts of divine providence and self-disclosure to particular individuals in the course of history. Special acts of God and Divine self-disclosures have huge moral and religious significance and make momentous differences in the course of human events; but this type of dependence is particular, not universal.

Acts of God and Divine self-disclosures involve interactions between God and created individuals in specific situations and lack the universality required to count as sustaining the universe; since they occur within an established universe, they do not count as world-creation; but they are instances of ongoing Divine creativity and the world's contingency upon God. Some critics suggest that Process Theology cannot allow for personal historical interactions between God and human individuals, ${ }^{16}$ but this is not true. The world may depend in special ways on God for what it knows about how God has related himself to particular people in particular times and places. As Charles Hartshorne explained:

With Crisis Theology ... our theory can agree that God is personal and selfrelated to the creatures, and that his acts of self-relationship are not rationally deducible, but require to be "encountered." However, as Barth and Brunner seem not to see, this is compatible with there being an essence of God which is philosophically explicable and knowable. The concrete volitions of God may be contingent... For each man-religion is a matter of the actions of God as self-related to him, that is, to a wholly contingent being, or to humanity, likewise contingent. Relations whose terms are 
contingent can only be contingent. Philosophy seeks that general principle or essence of the divine being of which such concrete actions of God are mere contingent illustrations. But from a religious point of view, it is the illustrations that count. Thus the religious and the philosophical attitudes are complementary, not conflicting. Our doctrine appears, then to effect a peculiarly comprehensive synthesis of past and present thought concerning theism. ${ }^{17}$

The success or failure of any act of divine self-disclosure depends upon the openness of human receivers to God. Some Christian Process Theologians hold that Jesus was both fully man and fully God in the sense that he was the one man in all of human history who was most fully open and sensitive to God's nature, thoughts, values, sensitivities, emotions, desires, and decisions. The historically limited and conditioned intellectual, aesthetic, moral, and religious capacities, predispositions, and perceptivity of human receivers and interpreters always color and may even distort divine disclosures. Sinners who may distort the message are always on the receiving end of divine communications.

To return to the objection that an everlasting universe would be a necessary being, recall that if a thing exists contingently, this means that (1) its nonexistence is possible or conceivable without contradiction; (2) it is caused to exist or created in some or all respects by something other than itself; (3) it is corruptible and destructible; and, normally, it (4) comes into being in time and (5) perishes or is capable of perishing in time. A necessary being has just the opposite properties. A temporally infinite set of contingent things, for example, contingent but successive universes, would not be a necessary being because (1) its non-existence is possible or logically conceivable; and thus (2) its existence is not fully self-explanatory. It is (3) destructible in principle unless some Necessary Being sustains it, or causes it to be self-sustaining once created. If a temporal set of universes is infinite, (4) (a) each part (each epoch) would come into being in time, albeit infinite time; (b) no part of it would be absolutely uncreated and persist through all time. (5) Still, the whole of it would embrace an everlasting past; and it would in this respect resemble the everlastingness of a single necessary being. If (6) it continues infinitely into the future, the whole would not perish in time, even though each of its parts does, so in that respect also it would also be everlasting. Still, it fails in many important respects-(1) through (4)-to be a fully necessary being.

Most importantly, ours is not a temporally infinite universe. Remember the Big Bang! The most crucial cosmological fact about our universe is (2) above. The one and only universe that we know to exist was caused to exist by something other than itself. The first premise of our cosmological argument applies to it. If any whole is composed entirely of contingent parts, that whole is itself contingent. Many ways in which our universe depends on God have now been identified. 
Would an infinite string of universes depend on God the way ours does? No available evidence supports the claim there is or was an infinite string of universes in either space or time. Infinity is not a real problem for our spatiotemporally finite universe, the only one we know to exist. Epistemologically, infinite universes are just postulates proffered to avoid God by atheists, or to imagine how God could be infinitely creative in space as well as time by Process Theists. Our problem is, What caused our Big Bang?

\section{B. Contingent Wholes Do Not Imply Necessary Causes}

At least one difficulty with applying "If the parts are contingent, the whole is contingent" premise to our universe is serious. Applying the Principle of Contingent Wholes to the universe as a whole enables us to conclude that it, too, is a contingent whole that has a cause. Yet, one way of applying it-as an inductive generalization-seems highly problematic

Recall that inductive logic allows us to generalize to more of the same, but it does not allow us to infer something different. The Principle of Contingent Wholes is an empirical truth derived inductively from what is "evident to our senses" about relations between parts and wholes within our own world of spacetime. When we extend it to apply to the universe as a whole, we are still reasoning from parts to wholes, so what is the problem?

The difficulty is with respect to the nature of that cause. Here, even if sofar-so-good with respect to reasoning from parts to wholes, other inductive generalizations seem to count against a Necessary Cause. Empirically, all experienced wholes derive their existence from other contingent beings, not from a necessary being. Thus, it seems, we are warranted inductively to generalize only that all contingent empirical wholes are caused by other contingent entities. Applied to the universe itself, this means that even if our contingent universe had a cause, we are warranted inductively to infer only that a contingent being (or beings) brought our world into existence. If this is all we are entitled to infer, the first premise of our Cosmological Argument from Contingency cannot generate the conclusion that a set of contingent beings or wholes, whether finite or infinite, depends ultimately upon a necessary being that transcends that set.

So, how does omnipresent contingency entail the reality of a transcendent necessary being? Inductive logic will take us from wholes to their causes, but will it take us from contingency to necessity? If not, Naturalism is in the same boat; it can't get the necessity of Nature by inductive reasoning either. Recall Naturalism's claim that "Nature as a whole exists necessarily."

In response, the existence of a necessary Divine Being is not an inductive inference. Even though it cannot be inferred inductively, it is still the most plausible explanatory hypothesis available to us. From contingency and finitude alone, neither Theists nor Naturalists can derive the infinity and necessity of 
God or Nature by direct observation or inductive inference. Still, they might get them as the most plausible explanatory hypothesis, that is, by abduction. Who has the best case?

Some analogies between nature and its parts seem to hold, for example, if any whole is composed entirely of contingent parts, the whole itself is contingent. Many other analogies cannot hold between intra-universe and extrauniverse causation. Not counting miracles, if there are any to count, experience shows that all empirical contingent wholes are caused by other empirical contingencies; but we have good reasons for not applying this very different generalization to the ultimate cause of the universe as a whole.

Many valid inductive generalizations cannot be applied to the ultimate cause of our total universe. Experience shows that all wholes within our universe are caused by other beings inside the universe. Yet, the universe as a whole cannot be caused by something within itself. The universe as a whole could not be caused to exist by another being (or beings) inside the universe because they are effects of the universe's existence, not its cause. Even cosmological Naturalists do not resort to that. Before Big Bang theory, they said it has always been around in some form, which isn't true. Now, they say, something transcendent like Superspacetime or an Antecedent Universe caused our Big Bang about fifteen billion years ago, but they do not claim that something within it caused it to be. Even Big Accident Theorist do not claim that something within our universe caused it to be; rather, it had no cause at all.

Another inductive generalization that applies to all wholes within our universe could not hold true of the ultimate cause of the universe itself. All wholes within our universe are caused by a finite set of natural events that go back no further than the Big Bang, but naturalistic oscillationists and all other infinitely many worlds metaphysicians postulate an infinite set of antecedent conditions as the ultimate cause of our universe. Naturalists deny both that nature as a whole is caused either by a finite set of causal conditions or by conditions that are parts of our own natural system of spacetime. They think that as whole it just isn't caused at all; it is itself the Necessary Being; like God, nature is "self-caused." But this is where the first premise of our Cosmological Argument from Contingency shows them to be wrong: all contingent wholes, nature included, have causes.

Many other inductive analogies of causation do not hold when dealing with the origin of the universe as a whole. All causes within nature are spatiotemporal; but singularities are not spatiotemporal. All causes within nature obey the lows of quantum physics; but antecedent and contemporary "many worlds" may have their own very different laws. The truth is, characterizations of the very nature of the ultimate cause (an infinite set of crunching antecedent universes, perhaps correlated with an infinite set of initial singularities, infinitely many co-existing worlds, an infinite and self-sufficient Nature, or what have you) are explanatory hypotheses, not inductive generalizations. 
The same is true of God as the ultimate Necessary Being. So the question is, which explanation is best? Preceding chapters demonstrated that non-theistic explanations just do not work.

That our universe as a whole had a cause is denied by Big Accident Cosmologists, who say that it just popped into being without a cause, and in a peculiar way, by Naturalists, who say that it is itself the self-sufficient Necessary Being. Both have been refuted in earlier discussions. Our reasoning about nature as a whole cannot be entirely nature bound. The cause of our universe was not the universe or some part of itself, not some finite set of causal conditions, and not a contingent set of conditions because no such entities are ultimately self-explanatory.

In one respect, Process Theology can easily accept contingency as an element of that which created our universe. As indicated earlier, most Process Theists affirm the reality of infinitely many temporally successive worlds or cosmic epochs on theological (but not empirical) grounds. It is reasonable to expect that an infinitely loving, social, and creative God would be infinitely creative of creatures to love and with whom to socialize. In a very important sense, "All contingent wholes have contingent causes" applies even to God; but this is not embarrassing to Process Theology as long as it is not the whole truth-as next explained.

An element of contingency pertains to God's creating all particulars. God's decisions to create particular actualities belong to God's contingent Consequent Nature, not to God's necessary Primordial Nature. God's decisions to create particular worlds are freely and contingently made. Particular manifestations of God's causal efficacy are contingent, not necessary. That the Divine cause of our universe is contingent, in part is compatible with the dominant process view that God creates new contingent worlds out of old contingent worlds, as well as with the oscillationist position that contingent old worlds enter into the creation of new worlds. In fact, most Process Theists have been implicit if not explicit oscillationists who think that God had important contingent roles to play in an infinite string of previously existing contingent universes or cosmic epochs.

The element of contingency in the God who created our finite and contingent world cannot be pushed too far. Not everything about God is contingent, or God himself would fall prey to the first premise of our Cosmological Argument from Contingency: God would also be a totally contingent being if everything about God is contingent; but there is an important disanalogy between Divine and mundane causation. If a totally contingently God caused our universe, then the world plus God would constitute another contingent whole requiring a higher order God as its cause. This higher order God is either contingent or necessary. If contingent, the Principle of Contingent Wholes applies again. No matter how many totally contingent Gods exist, the principle continues to apply until we come at last to a necessarily existent God. All contingen- 
cies, no matter how many, are swallowed up by the Principle of Contingent Wholes; and the process comes to rest only in a Necessary Being. No contingent wholes are self-existent or self-explanatory.

If our finite universe as a whole depends on God either originally, continuously, or historically in any way, the claim that "All contingent wholes are caused by contingent beings" is only part of the truth. The whole truth requires us to add, "And by a necessarily existing God." The most plausible explanation is that our universe depends for its existence and order on the reality of a transcendent Divinity who could not not exist, who knew what it was doing, did it intentionally, and did it well.

\section{C. "Cause" Cannot Apply to the Universe as a Whole}

With no necessary natural wholes or parts, our world is doubtless derived causally from something other than itself; but another small problem remains. Perhaps the very notion of causation makes sense only when applied within the universe and cannot be applied to the universe as a whole. Experienced causes are always associated with space, time, and natural laws; but all of these disappear at $\mathrm{T}=0$ if the universe as a whole is created by a Divine transcendent reality out of absolutely nothing or the empirical nothingness of a singularity.

An analogy between God and an initial singularity as the cause of the universe may help us to understand how God can be its cause. Recall that some versions of "scientific" Oscillation Cosmology affirm that an antecedent universe collapsed into a singularity and then caused our universe on the rebound. The existence of neither a single antecedent universe nor a self-sufficient infinite totality of prior universes can be established scientifically. Everything to which science appeals in tracing causal connections just plays out at an initial singularity. A singularity is spaceless, timeless, and lawless; and without space and time, the concepts of physical energy, causation, and natural laws are meaningless. Thus, even in this "scientific" account, our system of spacetime erupts from something nonspatiotemporal, nonphysical, and nonnatural.

Given an initial singularity, our space and time begin just this side of $\mathrm{T}=$ 0 ; and it makes no sense to say that the initial singularity was earlier than the onset of the primordial fireball itself. Nothing can be temporally earlier than the first moment of time, neither a singularity, nor an antecedent universe, nor an atemporal God. According to George Mavrodes, an initial singularity must have the same relation to creation that God has in Augustinian/Thomistic Classical Theism. ${ }^{18}$ It is a logical, theoretical, hypothetical, metaphysical-but not a temporal-prerequisite for all space, time, and physical energy and causation.

Natural or physical causation also plays out at an initial singularity. Being the effect of something natural, of spatiotemporal energy, can be traced back no further than the very first "products" of an initial singularity. Scientific or empirical knowledge of natural, that is, spatiotemporal causes terminates 
abruptly at that point; no spatiotemporal or natural causes exist where no spacetime exists at all. Looking backward, all scientific knowledge based upon natural causal relations ends where natural causes begin. A singularity is a nonphysical, non-spatially extended cause or ground of everything physical.

If, as many scientific cosmologists hold, the habits and laws of nature are themselves products of a colossal cataclysmic explosion that emerged from we know not what, there can be no natural law for-or underlying-creation itself. Natural laws themselves are (very abstract) creatures, no matter whether God, an initial singularity, or an antecedent universe produced them. As John Wheeler cautioned, "There never has been a law of physics that did not demand 'space' and 'time' for its statement.... With the collapse of space and time the framework falls down for everything one ever called a law of physics."'9

If we extrapolate mathematically from observationally confirmed laws of Hubble expansion, the redshift of the galaxies, and cosmic entropy, then make proper allowances for an increasing (once thought to be declining) pace of expansion as the explosion winds down (or up!), and finally calculate retroactively the past natural history of the cosmos, we arrive at zero space and time somewhere close to fifteen billion years ago. Natural laws take us back that far, but they can carry us back no further than the point at which they themselves originate. Thus, we cannot extrapolate scientifically back to even one antecedent universe, much less an infinite number of them. Scientific knowledge ends at $\mathrm{T}=\mathbf{0}$, or just this side of it. From our perspective within this world, an initial singularity, antecedent universes, and a transcendent Superspacetime are supernatural, atemporal, non-natural-causal entities, just as God is in Classical Theology. They may be just two ways of thinking about the same thing-an initial nonphysical cause or pre-condition of the universe.

Nothing remains of the notion of physical or natural causation once space, time, physical energy, physical causation, and natural laws are eliminated; but this is no embarrassment to Theologians, for whom the creation of the universe ex nihilo had a transcendent Divine cause, not a natural cause. If cosmological reflection comes to this, the theologians can say: "I told you so."

Natural laws can not "govern" or enable us to predict something that happens only once. The unique creation of a unique universe is more like the expression of choice or will than an effect of lawful physical regularities; but a puzzle lingers. Does any meaning remain for "cause" after its natural associates-space, time, physical energy, and natural laws-are altogether expunged? Can "cause" still have metaphysical meaning when stripped of all natural or physical meaning? Some critics think not. A Classical Theist might reply: "Well, I hope so; but if it doesn't, the singularity of Antecedent Universe Cosmology is in the same boat. God, who caused the Big Bang, is somehow a necessary condition for the existence of our universe." Yet, just what this "somehow" means is less than clear. 
Process Theism, or some form of temporalistic theism, has a much easier time with such puzzles of causation and creation. George Mavrodes concedes, perhaps somewhat grudgingly,

If God Himself is a temporal being, sustaining temporal relations, then indeed there can be time outside of the singularity. And God, the cause of the existence of the world, can temporally precede the existence of the world. ${ }^{20}$

Divine spatiality could also exist literally outside our world as ali-embracing Divine Superspacetime; the temporal God of process theology is everlastingly embodied. Our finite universe may be and likely is only one part of God's body.

Divine causation could be non-physical or "incorporeal" as Classical Theology maintained; but if efficient causation is unintelligible without space, time, and embodied energy, then Process Theism attributes all of them everlastingly to God and thus can make theoretical sense of initial Divine transcendent but still spatiotemporal causation or creation from God's Superspacetime to our spacetime.

But our inquiry is not quite complete. Until both Divine and non-divine transcendent but contingent causes are ruled out, our Cosmological Argument from Contingency does not come to rest in God as a Necessary Being who always was and ever will be.

\section{God Also Must Have Had a Cause}

If everything has a cause, then God has a cause. So, who or what caused God? Naturalistic cosmologists really seem to savor this common objection to Theism. Carl Sagan expressed it nicely in his Cosmos.

In many cultures it is customary to answer that God created the universe out of nothing. But this is mere temporizing. If we wish courageously to pursue the question, we must of course ask next where God comes from. If we say that God has always existed, why not save a step and conclude that the universe has always existed? ${ }^{21}$

Sagan's question ignores several important things. First, we know from Big Bang theory that the universe has not always existed. It is only fifteen billion or so years old. Just pronouncing that our universe is eternal cannot overcome that. Next, even if the universe were infinitely old, it would still be contingent because it depends on God in various ways at every moment, as previously explained. Sagan's premise-Everything (even God) has a cause-is inconsistent with his conclusion-The universe has no cause ("has always existed," as Sagan put it). If everything has a cause, then the universe has a cause. 
Even Sagan does not really want to say that everything has a cause. Sagan's atheistic Naturalism supposes that our necessarily existing universe had no cause; but this is false. That our universe is an everlasting necessary being is decisively falsified by all the evidence supporting Big Bang Cosmology. Finally, Sagan misunderstands the concept of God. Nothing falsifies God's existence. God, unlike the universe, has always existed because God is that being who could not not exist. As St. Anselm discerned, if it were possible for God not to exist, God would not be God, the supremely worshipful reality than whom none greater can be conceived. Sagan's analogy between contingent and necessary being does not work!

The desire to "save a step" cannot change a world that every human experience shows to be contingent, temporal, finite, and capable of non-existence into an everlasting world that could not not exist. The very idea is self-contradictory. By contrast, neither experience nor logic conflicts with the concept of God as the one reality who could not not exist and who is causally self-sufficient, uncreated, everlasting, and indestructible. Experience clearly discloses that the world does not resemble God's everlasting and self-sufficient Primordial Nature in any of these ways. Nature does not manifest these divine attributes, and we cannot make an unworkable analogy go through merely to "save a step." Experience and inductive extrapolation show that our universe is a contingent entity, and no ingenious conceptual gerrymandering can alter that brute fact.

Poor philosophical reasoning is repeated interminably in cosmology. In The Blind Watchmaker, Richard Dawkins argues that it is futile to appeal to God to explain features of the world like DNA and proteins because this

leaves unexplained the origin of the Designer. You have to say something like 'God was always there,' and if you allow yourself that kind of lazy way out, you might as well just say 'DNA was always there,' or 'Life was always there,' and be done with it. ${ }^{22}$

But we know for a fact that DNA and life were not always there, and saying so does not make it so. They are contingent wholes that require causes beyond themselves. Similarly, when Paul Davies considers the Theistic claim that God is the necessary being who has within himself the explanation of his own existence, he asks, "Why can't we use the same argument to explain the universe?"23

The answer is, the fifteen billion-year-old universe is composed entirely of contingent beings; and any whole composed entirely of contingent beings is a contingent whole, as experience clearly shows. We know that our world's existence is not everlasting, self-sufficient, or self-explanatory; and that is why we cannot use the same concepts to explain the universe that we use to explain God, whose Primordial Nature exists necessarily.

Stephen Hawking grew increasingly agnostic if not decisively atheistic over the years. ${ }^{24}$ Hawking suggested in A Brief History of Time that there is 
really nothing for God to do if his "no boundary" proposal for cosmology is correct.

So long as the universe had a beginning, we could suppose it had a creator. But if the universe is really completely self-contained, having no boundary or edge, it would have neither beginning nor end: it would simply be. What place, then, for a creator? ${ }^{25}$

We should now understand why Sagan, Dawkins, Davies, and Hawking are philosophically confused. A universe unlike ours with no beginning or end nevertheless would exist contingently if, like ours, it were composed entirely of contingently existing parts. The contingency of any universe like ours that had a beginning should be patently obvious. Our universe also contains no parts that exist necessarily-without any causal dependence of any kind on anything. A contingent universe with or without a beginning still needs God; and our universe had a beginning.

\section{E. Atheism Is Simpler than Theism}

Philosophers and scientists alike appeal to the Principle of Parsimony or Simplicity as a significant norm of rational explanation. Ockham's razor, as it is often called, says that we should not multiply explanatory entities unnecessarily, that our explanations should be as simple as possible. The lure of simplicity is as much aesthetic as rational. It is where the true and the beautiful come together. Yet, the ideal of simplicity must always be balanced by the norm of comprehensiveness, for we should not oversimplify. As Whitehead suggested, we should "Seek simplicity and distrust it."26

Naturalists may want to argue that the hypothesis of an infinite and selfsufficient nature or cosmos is simpler than the hypothesis of a contingent universe plus God. Pierre Simon Laplace, who believed in a self-sufficient and everlasting system of natural causes, told Napoleon that he had no need of the God hypothesis. Unfortunately, the naturalistic hypothesis is not scientifically verified or verifiable; in fact, it is falsified by Big Bang Cosmology. And neither an infinite single world nor infinitely many worlds is simpler than one infinite God. To avoid God, atheists have to resort to infinity-to something just as complex as God!

Simplicity is determined by counting either the number or the complexity of explanatory entities, or both. A theory with fewer or with less complex explanatory entities is simpler than one with more. Naturalist may reject theism on the grounds that one world alone is simpler than one world plus one God. Obviously, one is simpler than two. But things are not so simple. The universe of Naturalism is either one infinitely complex world, or infinitely many finite worlds. Is this really simpler than Theism's minimal postulate of one world and 
one God? The answer is complicated by the fact that this one God is said to be infinitely complex in Process Theism and infinitely simple in Classical Theism.

In arguing that Theism is not as simple as Naturalism, Naturalists may have in mind either the number of explanatory entities or their internal complexity. Complexity is a function of the number, kinds, and order of inner parts.

In number, one (finite) world plus one (finite) God is less simple than one (finite) world; so at this simplistic level, Naturalism wins the battle of simplicity; but, as already shown, Naturalists really do not believe in a finite world. The viable options for both Naturalism and Theism are much more complicated. Expressed in terms of contemporary cosmology, Naturalists are committed to either one infinite world (ours) or infinitely many finite worlds in a Superworld beyond and/or before ours. These options are very different; but which is the simplest? At the same order of infinity, a whole comprised of an infinite number of finite entities is just as complex as, indeed is numerically identical with, a single infinitely rich entity. Dennis Sciama argues that an infinite worlds metaphysics is simpler than a Theism in which God decides to create only one world because the it places as few constraints on reality as is compatible with observation. ${ }^{27}$ Sciama obviously confuses simplicity with plenitude and observation with concoction. Victor J. Stenger remarks,

Several commentators have argued that a cosmology of many universes violates Ockham's razor. I beg to differ. The entities that the law of parsimony forbids us from multiplying beyond necessity are theoretical hypotheses, not universes. The cosmology of many universes is more economical if it provides an explanation for the origin of our universe that does not require the highly nonparsimonious introduction of a supernatural element that has not heretofore been required to explain any observations. ${ }^{28}$

In reply, other universes are supernatural elements. And the standard objections are that theism multiplies the number of entities, not the number of hypotheses, and that it explains the existence of our world by appeal to an otherworldly being or beings. In both respects, however, there is no difference at all between God and infinitely many other worlds, except that God is numerically one, and the many worlds are numerically infinite. Stenger elsewhere characterizes the innumerable other worlds of many worlds metaphysics as "bizarre," "untestable," 29 and a matter of "uneconomical speculation." ${ }^{30}$ The Other Worlds of Quantum Cosmology are just as transcendent, supernatural, and inaccessible to direct sensory verification and warranted inductive inference as a transcendent God; and they outnumber God by infinity to one! So which hypothesis is the most "nonparsimonious"?

If we shift focus from extensional referents (things) to intensional meanings (hypothetical constructs), exactly the same point applies to hypotheses as to entities. Epistemologically, as explanations of the origin of our universe, God 
and infinitely many worlds are both theoretical hypotheses; and the claim that only the God-theory is really a theory is question-begging nonsense. Stenger's argument against God-as-a-theory is like dismissing evolution because it is just a theory.

The strongest and most appealing forms of Theism really do not conceive of God as infinite in every conceivable or verbalizable respect. God is infinite only in every logically consistent respect compatible with supreme goodness and worshipfulness. In number of explanatory entities, one infinite world alone seems at first to be simpler than one or more infinite worlds plus one infinite God, for one is simpler than two. We are habituated to finitistic thinking, but we are now dealing with infinities that do not sum up like finites. Infinity added to infinity just equals infinity. In complexity, it is not at all obvious that one infinite world is simpler than one infinite world plus one infinite God.

Richard Dawkins also failed to consider infinities when he argued that God is more complex, thus less simple, than the world. In his words,

Any God capable of intelligently designing something as complex as the DNA/protein replicating machinery must have been at least as complex and organized as that machine itself. Far more so if we suppose him additionally capable of such advanced functions as listening to prayers and forgiving sins. ${ }^{31}$

Where infinities are involved, determining simplicity and multiplicity or complexity requires the use of transfinite mathematics. Most critics of theism fail to consider this, which is why Naturalists often seem to win the simplicity contest. In transfinite mathematics one infinity plus another (or plus any finite number) is equal to one infinity, assuming that the infinities are of the same order; so one infinite God plus an infinite world has no more members than an infinite world alone, or an infinite God alone. If God's infinity is of a higher order than the world's, then God plus one or more infinite worlds is equal to God's more complex order of infinity. The sum is still just one infinity. When infinities are totaled, no matter how many, they always sum up to one infinity, and one is the paradigm of numerical simplicity. All the foregoing options seem to be equally simple.

A further complication with respect to the complexity of explanatory entities must be considered. Classical Theists insist that God is absolutely simple in himself; only our thoughts about God are complex. In himself, God is somehow pure undifferentiated unity of being, and that constitutes God's simplicity. So what could be simpler than that? Well, we hardly know how to assess the meaning or the simplicity of such double-talk. By contrast, Process Theism drives no absolute wedge between God and our thoughts about God. We think of God as infinitely complex because God really is infinitely richer in properties than all lesser beings. God is more complex than an infinite world, 
for God's infinity is of a higher order than the world's. Theological comprehensiveness, explanatory power, and correctness sometimes demand complexity at the expense of inordinate simplicity.

So, is a naturalistic infinite-world-ensemble metaphysics really simpler than Theism? Where the order of infinity is the same, in number of explanatory entities, Naturalism's infinitely many worlds without Divinity are certainly no simpler than Creation ex nihilo Theism's one infinite God plus one finite world because God's infinity plus a finite unit (one finite world) just equals God's infinity.

Considering only the number of worlds involved, naturalistic infinite worlds metaphysics, not Theistic creation of our one world ex nihilo, egregiously violates Ockham's razor. One-world monotheism clearly wins the simplicity contest. One finite world is infinitely simpler (less numerous) than an infinity of worlds.

Process Theists postulate a loving God's creative involvement with an infinite number of worlds to love. This gives us an infinite God plus an infinity of worlds, but these sum up to one infinity, God's. In complexity of ultimate explanatory entities, infinitely many finite worlds considered as a totality would not rival God's own infinite complexity if God's richness belongs to a higher order of infinity. If their order is the same, they are equally complex.

No matter what, that Naturalism is simpler than Theism is by no means evident. To avoid God, non-theists must appeal to something almost if not entirely as rich and complex as God.

The most simple-minded naturalistic atheistic metaphysics would affirm the existence of a single completely self-contained, self-sufficient, and everlasting but totally finite world without Divinity; but this metaphysics is incoherent because infinite time, required for everlasting self-sufficiency, is incompatible with total finitude. Older Naturalists postulated the infinite duration of our one world, but the Big Bang came along. Naturalists are now driven to postulate infinitely many transcendent worlds-while still complaining about traditional religion's other worlds! The actualized infinity of infinite worlds metaphysics is not verified, not verifiable, lacks an Agent of Diversification and Selection, and fails to account for the remarkable fine-tuning of our universe for the production of complex valuable life. Creation ex nihilo Theism is the simplest theory that can account for our well-ordered world and satisfy rational explanatory norms of both simplicity and comprehensiveness, but even it must come to terms with the concept of God as infinitely creative.

\section{F. There Is No Universe as a Whole}

Kai Nielsen contends that the very notion of the universe as a whole is unintelligible. If true, this implies that the idea that anything, including God, created or caused the universe is also unintelligible. If he is right, the whole project of this 
book, the search for the cause of the origin of our universe in the Big Bang, is totally misguided; and its conclusion, that God did it, is utterly unintelligible. As Nielsen expresses the argument:

It is only by thinking of the universe as some kind of gigantic thing or some kind of entity or totality that we can have a shot at intelligibly speaking of the universe as a whole. But "universe" may be just an umbrella term for the various things, events and processes there are. We cannot intelligibly speak of the sum of things so that we could intelligibly speak of them as a whole and ask if, and, if so, how, this universe was created and is sustained. Moreover, since the universe is not an object, event, process-not any kind of entity at all-there is no such thing as the universe for "universe" to stand for. Rather the term "universe" is an umbrella term standing for the objects, events, and processes there are. But there is no sense to trying to count the number that there are and to come to speak of the universe as a whole. "Universe" does not stand for some mysterious entity, but indifferently for those various discrete things. Things of which, since "object" is not a count word, we cannot count the sum. There is, that is, no way of summing them up and fixing the number of them that there are. This being so, we cannot coherently speak of the universe itself-that totality-being caused, created, sustained, and the like. To ask for the cause of the universe is to make what in the good old Ryleian days would have been called a category mistake. ${ }^{32}$

This argument suffers from many defects. First, Nielsen assumes that the only way to give meaning to the notion of the unity of nature, the universe as a whole, is to be able to count the number of its ingredients. This is itself a significant departure from the views of traditional Naturalists, who consistently identified nature or the universe with our system of space/time and all of its ingredients, no matter how many, and no matter whether they are practically countable. Naturalists traditionally claimed that this system of nature infinitely or eternally predated our existence. Traditional Naturalists would grant that we probably cannot count all natural things, events, and processes, even in principle (except perhaps by using transfinite mathematics, which really is a way of counting); but this would not persuade them that the concept of nature as a whole is unintelligible. Nielsen disagrees. Perhaps he thinks that the entities within the universe are not countable because they are infinite in number and cannot be counted finitistically, even in principle. Or he may think the rich natural order of things, whether finite or infinite, is so lacking in unity that thinking of it as "a whole" makes no sense. Either way, he is mistaken. Infinity is also a way of counting; but our universe is finite; and it has much more unity than Nielsen allows. 
Our universe is not infinite in time, space, or number of real parts; and strategies are available for making the unity of the concept of the universe as a whole perfectly intelligible. Nielsen seems to ignore contemporary Big Bang Cosmology completely. It has developed and explicated these strategies for us in great detail, as by now we well know. We need not be capable in practice of counting the number of things in the universe in order to know many things that make the concept of "the universe as a whole" intelligible. (1) Everything within our system of spacetime had a common, intensely concentrated, and totally unified origin. (2) All cones of causation within our contemporary universe are derived from an original grandly unified Big Bang. (3) By extrapolating from pervasive laws of nature, we can trace the common evolutionary physical history of everything within our system of spacetime back to highly unified Big Bang origins. (4) This history goes back for approximately fifteen billion years and no further. For details, read again Chapter One of this book and subsequent discussions! Nielsen finds unintelligible what contemporary astrophysicists find exceedingly intelligible! And they show us exactly how to conceive meaningfully of our universe as a unified whole.

Nielsen has not learned an important lesson from contemporary "scientific" astrophysics and cosmology: asking about the duration of the totality of what he calls "the objects, events, and processes there are" makes perfectly good sense. Without being able in practice to count each of them individually, traditional Naturalists gave this answer: Their collective duration is infinite; our universe has existed throughout an infinite past. Nielsen may presuppose this without making his commitment explicit; perhaps he half-consciously hopes that no one will pry too deeply into the topic. Contemporary cosmologists both ask and effectively answer the question. The totality of "The objects, events, and processes there are" has endured for only fifteen billion years or so, no longer, and certainly not forever. All of the overwhelming evidence for the Big Bang given in Chapter One of this book attests to this conclusion.

Since the notion of our universe as a whole really does make sense, and since traditional Naturalists were clearly wrong in insisting upon its infinite duration, the question of a transcendent cause or creation of the universe is intelligible after all. Even atheistic Oscillationists and Quantum Cosmologists think so. Even cosmological atheists affirm a transcendent causes or causes of our universe, as previously explained. But was it God? That is the viable issue.

Consider one of Nielsen's principle arguments against the supernatural. "It isn' $t$ that we do not have to go beyond nature, but that we do not understand what such talk comes to. We have no idea of what it would be like to go beyond nature." ${ }^{33}$ To find out what it would be like, all Nielsen has to do is ask any Oscillationist or Quantum Cosmologist. Atheistic supernaturalism is rampant in contemporary astrophysical cosmology. For Theism, transcendence is no problem because even a scientifically well informed Naturalism is unintelligible without it. 


\section{G. Transcendent Reality Is Unknowable}

Immanuel Kant contended that all arguments for the existence of God fail because they apply conceptual categories of the understanding-like causation, purpose, and necessity, which legitimately pertain only to appearances-to real things in themselves. For Kant, all reality is experientially, causally, spatially, and temporally transcendent and theoretically unknowable; only appearances are knowable, spatial, causal, and temporal. Kant believed that appearance and reality in no way resemble one another with respect to spatial, temporal, causal, and all other metaphysical properties and relations.

The problem is, if all spatiotemporal and causal properties and relations are removed from our concept of reality, or from reality in itself, nothing is left. Since "being" is also a Kantian category of the understanding that applies only to appearances, not even being is left! Kant rejected all cosmological attempts to know the real world of nature, along with critically realistic theories of perception according to which appearances are like realities at least in being spatiotemporal and in being caused by the realities they resemble. Kant rejected philosophical and scientific realism in epistemology, cosmology, and theology largely because they apply the concept of "cause" to realities; but when ask why he must introduce real things in themselves at all, his answer was that they have to be there to cause us to have the perceptions or "appearances" that we have.

Critical Realism applied to cosmology does not conceive of transcendent reality as something merely beyond or before our sensory perceptions. Instead, transcendent reality is "beyond" and "before" our objectively existing world of nature, our universe, our cosmos, our very real system of space/time/mass/ energy. This is what "transcendent" meant traditionally in both theistic and naturalistic metaphysics. Nature is our public, objective system of spacetime, as opposed to the private spacetimes of dreams and hallucinations and the inaccessible spacetimes of transcendent Other Worlds. Nature includes all things that exist within and have causal relations with at least some other entities within our public world; and anything that transcends this world is supernatural. Even if it has causal relations with it, transcendent reality either logically or temporally antedates our system of spacetime and has no fixed or ascertainable limited position within it. In Process Theism, the eternal Primordial Nature of God is always embodied in some concrete, contingent, spatiotemporal Consequent Nature; it is a necessary condition for every particular contingency in our world; yet it both transcends and is immanent in all actual worlds-if God, who alone knows for sure, has created more than one.

Scientific Cosmological Agnosticism, we saw in Chapter One, indicates that we can really know many features of our objective spacetime system scientifically, but we cannot have scientific knowledge of transcendent realities like Other Worlds, whether the otherness be supertemporal, superspatial, or both. Can we then have no rational or philosophical knowledge at all of the transcen- 
dent? If not, Teleological and Cosmological Arguments fail, for the God who allegedly caused our Big Bang and ordered our universe is a transcendent reality. Most contemporary "scientific" cosmology also fails if transcendence is beyond all human knowledge. Like God, antecedent or co-existent universes are transcendent realities, if real at all. The God hypothesis is a philosophical, not a scientific, explanation of our universe. So is any version of infinitely many Other Worlds. The world disclosed to us in natural science leads to the very edge of scientific knowledge and demands a rational philosophical explanation that natural science cannot give.

What caused the Big Bang itself to erupt? What caused a life-supporting universe instead of chaos or lifelessness to issue from the Big Bang? Physical science poses the questions, but it cannot answer them. Science periodically answers previously unanswered questions, but "What caused the loaded-for-life Big Bang?" is unanswerable in principle by natural science; its methodologies just do not extend that far. Can philosophical reflection do any better? Theistic meta-physics (after-physics) replies that some transcendent-imminent Ultimate Reality who knew what it was doing was responsible. Neither the God hypothesis nor that of infinitely many worlds is directly or inductively verified empirically; both postulate unseen transcendent or supernatural realities to explain the origin of our universe. But, all things considered, (as we have done!), the God hypothesis is the best explanation.

A life-supporting universe might happen by pure accident, given an infinite number of diversified universes. But we have no good reasons for giving that, and mere infinity requires an Agent of Diversification to yield a life-supporting universe. Logical possibility as such says nothing whatsoever about empirical probability. Mere infinity contains no Agent of Selection and Diversification. Infinitely many worlds metaphysics cannot explain why our orderedfor-life world exists or why lifeless universes are not repeated infinitely many times; it cannot guarantee an infinite diversity of individuals, their qualities, and their relational combinations. The Plenitudist notion of realizing all possibilities is not logically coherent. Pure infinity requires no diversity at all, much less the kind that selects for life. Plenitude is merely a ghost without a machine.

A teleological explanation of the life-supporting cosmic coincidences of our finite but well-ordered universe is needed; a personal, intelligent, benevolent, and life-loving Agent of Diversification and Selection best explains the origin and structure of our exquisitely designed contingent universe. That our world was designed for life-flourishing by a Divine, supercosmic, supercalculating, life-loving intellect is the most plausible hypothesis, the explanation best supported by a preponderance of the anthropic, cosmological, and philosophical evidence. Without a supercalculating God, our life-supporting universe would be infinitely improbable; and reason rejects infinite improbabilities. Reasonable persons certainly may, and perhaps must, come to this conclusion: God caused the Big Bang. 